\title{
Impact of Senior Dance on emotional and motor parameters and quality of life of the elderly
}

Impacto da Dança Sênior nos parâmetros emocionais, motores e qualidade de vida de idosos

José Alípio Garcia Gouvêa ${ }^{1}$, Mateus Dias Antunes ${ }^{1}$, Flavio Bortolozzi ${ }^{1}$, Andrea Grano Marques ${ }^{1}$, Sônia Maria Marques Gomes Bertolini ${ }^{1}$

Objective: to verify the effects of Senior Dance on cognitive and motor parameters and quality of life of elderly people. Methods: pre-experimental study with pre and post-test for a group with a convenience sample composed of 20 elderly of both genders. Participants were evaluated through the agility test, the balance scale and inventories of depression and anxiety, and a questionnaire on quality of life. Elderly people participated in a physical activity program featured as Senior Dance for a period of three months. Results: the intervention resulted in improved scores in most of the variables, with significant results only for anxiety classified as temporary emotional state. Conclusion: Senior Dance was effective as physical exercise to improve the quality of life, as well as the physical and mental health of the elderly.

Descriptors: Dancing; Postural Balance; Aged; Mental Health; Quality of Life.

Objetivo: verificar os efeitos da Dança Sênior sobre os parâmetros cognitivos, motores e na qualidade de vida de idosos. Métodos: estudo pré-experimental, com delineamento de pré e pós-teste para um grupo, com uma amostra por conveniência composta por 20 idosos de ambos os gêneros avaliados por meio do teste de agilidade, escala de equilíbrio e inventários de depressão, ansiedade e questionário de qualidade de vida. Os idosos participaram de um programa de atividade física caracterizado como Dança Sênior, por um período de três meses. Resultados: a intervenção apresentou melhores escores na maioria das variáveis, com resultados significativos apenas para a ansiedade classificada como estado emocional temporário. Conclusão: a Dança Sênior foi efetiva como exercício físico na melhora da qualidade de vida, saúde física e mental dos idosos.

Descritores: Dança; Equilíbrio Postural; Idoso; Saúde Mental; Qualidade de Vida.

${ }^{1}$ Centro Universitário de Maringá. Maringá, PR, Brazil. 


\section{Introduction}

Cognitive ability is one determinant of quality of life in old age, since losses in cognitive functions may result in impaired physical, social and emotional functioning of the elderly. Evidence shows that cognitive impairment is strongly associated with impaired mobility, as well as spatial disorientation and deterioration of executive functions. Physical exercise can improve mental health and contribute to prevent disorders such as depression and even dementia ${ }^{(1)}$.

In order to promote healthier aging, dance has been indicated as a form of physical activity. Dance is understood as art through body expression and determines the state of mind of people. Dance is related to improving the quality of life of the elderly, improving both the mobility and psychological problems as a result of socialization. This makes self-esteem of the elderly to increase, making them to leave a sedentary lifestyle to become more physically active ${ }^{(2)}$.

In 1974, a physical activity program called Dance Senior was created in Germany. The program was based on folk songs of diverse peoples and most often performed in circles, reliving childhood songs ${ }^{(3)}$. Dance Senior causes the elderly to work physically with planning, decision making and monitoring. These tasks relate the functional capabilities by using a systematized set of choreographies specially adapted to the possibilities and needs of the elderly ${ }^{(4)}$.

There is evidence that physical activities such as dance, which require in essence intense cognitive demand, such memorizing sequences of movement patterns and sustained attention to unintended changes in movements, have benefits not only to the muscular, skeletal and cardiovascular systems, but also the central nervous system, because of engaging the process of executive control ${ }^{(5)}$.

Physical and mental abilities have great synergy with the quality of life of older people. Through body language, such as dance movements, the elderly can benefit from social life, as well as benefit from intellectual and physical aspects ${ }^{(5)}$. The guiding ques- tion of the present study was: "What is the effect of the Dance Senior on cognitive and motor parameters and on the quality of life of short-stay elderly?". Thus, the aim of this study was to investigate the effects of the Dance Senior on cognitive and motor parameters and on the quality of life of the elderly.

\section{Methods}

This is a pre-experimental study with pre and post-test for a group carrried out from February to May 2014 in a convenience sample of 20 elderly of both genders. Participants were aged between 60 and 89 years and they are regular visitors of two short-stay institutions for the elderly known as Day Centre in the city of Maringá, PR, Brazil. A living space for low-income seniors is provided during the daytime in these institutions.

Inclusion criteria for selection of the sample were: apparently healthy elderly who were able to remain in the upright position, with ability to walk with or without assistance, whithout history of serious diseases (cardiovascular, endocrine, metabolic or neuromuscular). Regarding the exclusion criteria, elderly who had dementias, who were bedridden and users of wheelchairs were excluded. As criteria for discontinuation, elderly who did not attend $80.0 \%$ of the total number of classes were excluded from the study.

The elderly were assessed in two moments: the first assessment (pre-test) was done before dance classes, and the second assessment (post-test), after the intervention program that lasted three months.

The Berg Balance Scale was applied and serves to evaluate the functional balance of the elderly and patients with balance disorders. The scale contains 14 tasks common to the activities of daily living. It is composed of five alternatives with scores ranging from zero to four points (zero, unable to perform the test and 4 performs it safely). The score can range from zero to 56 points. The higher the score, the better the performance in the test ${ }^{(6)}$.

The Timed Up and Go test was proposed to eva- 
luate the balance, risk of falls and functional capacity of the elderly. Adult individuals that are independent and without impaired balance perform the test in 10 seconds or less. Those who are dependent on other to carry out basic transfers perform the test in 20 seconds or less. Finally, those individuals who need more than 20 seconds to perform the test are dependent on other for accomplishing many activities of daily living and mobility ${ }^{(7)}$.

To collect the data on the possibility of depression, we used the Beck Depression Inventory. This is a scale for self-assessment of depression with 21 items including symptoms and attitudes, each with four statements in degrees of intensity that go from 0 to 3. There are different proposed cutoffs for the Beck Depression Inventory depending on the nature of the sample and the study's objectives. In samples that have not received medical diagnosis of depression, such as the participants of this study, the literature recommends the following measures: $\leq 15=$ normal or mild depression; $16-20=$ dysphoria; $>20$ = depres$\operatorname{sion}^{(8)}$.

To evaluate anxiety we used the State-Trait Anxiety Inventory. State anxiety is characterized by unpleasant feelings of apprehension and tension consciously perceived that can vary in intensity according to the danger perceived by the person and the change in time. Trait anxiety refers to relatively stable individual differences in the tendency to react to situations perceived as threatening, situations that rise the intensity of the state of anxiety. It has a lasting effect in the person because, as a personality trait, anxiety is less sensitive to environmental changes and remains relatively constant in time. The total score of each scale ranges from 20 to 80 , wherein higher values indicate higher levels of anxiety ${ }^{(9)}$.

Quality of life was assessed through the WHOQOL-BREF questionnaire, a short version of the WHOQOL-100. This is composed of 26 questions of which two relate to the individual's perception of quality of life and health and the others (24) are distributed in four domains: physical, psychological, social re- lationships and environmental. The closer to 20, the better the quality of life in the assessed domain, and the closer to 100 , the better the overall quality of life ${ }^{(1)}$. Intervention with Senior Dance includes global movements that mobilize the joints, help the physical and mental balance, posture, gait and stretching. With the help of music, the Senior Dance estimulates the memorization of movements through the rhythms awakening social life, besides improving activities of daily living ${ }^{(4)}$. Classes lasted 45 minutes, were conducted three times a week for three months, resulting in a total of 40 classes. Welcome songs were used, including Seated Waltz and Mexican Waltz, with the elderly in the sitting position, and Tschok House in standing position. These used low-impact choreography, short and light steps and gentle movements, always respecting the limits of each participant, and the activity was completed with five minutes of stretching.

The protocol was divided into five stages and songs were worked sequentially: first stage (two weeks - 6 lessons) - Welcome songs; second stage (3 weeks - 9 classes) - Sitting Waltz song; third stage (3 weeks - 9 classes) - Mexican Waltz song; fourth stage (3 weeks - 9 classes) - Tschok House song; fifth stage (3 weeks - 9 classes) - all songs. The material used was a stereo and 20 chairs.

Data were entered in a Microsoft Excel 2010 spreadsheet and analyzed statistically with the Statistica 8.0 software. Normal distribution of the data was tested with the Shapiro-Wilk test. Means and standard deviations were evaluated for quantitative variables, to which the Wilcoxon test was used for pairwise comparisons. As for paired situations, frequency tables with percentage were used, followed by the McNemar test when necessary. The significance level used in the tests was $5 \%$, that is, associations with $\mathrm{p} \leq 0.05$ were regarded significant.

The study complied with the formal requirements contained in the national and international regulatory standards for research involving human beings. 


\section{Results}

Twenty elderly people participated in the Dance Senior and $65.0 \%$ of these ( $n=13$ ) were female and $35.0 \%(\mathrm{n}=7)$, male. The average age of women was $78.84 \pm 5.26$ years and of men, $78.42 \pm 8.27$ years. As for education, regardless of gender, $55.0 \%$ of elderly people could not read or write.

Table 1 shows the results of the effects of the 40 dance sessions in motor variables of the elderly, which obtained the highest scores in the post-test for the Berg Balance Scale $(\mathrm{p}<0.001)$ and for the Timed Up and Go test ( $\mathrm{p}=0.05)$, indicating an improvement in both, balance and agility.

Table 1 - Pre- and post-test results for the Berg Balance Scale and the Timed Up and Go test for elderly attending the Senior Dance. $\mathrm{n}=20$

\begin{tabular}{lcccc}
\hline Tests & Pre-test & Post-test & Difference (\%) & p \\
\hline $\begin{array}{l}\text { Berg Balance Scale } \\
\text { (score) }\end{array}$ & $44.05 \pm 0.5$ & $48.15 \pm 4.76$ & 9.3 & $<0.001^{*}$ \\
$\begin{array}{l}\text { Timed Up and Go } \\
\text { (seconds) }\end{array}$ & $15.74 \pm 11.22$ & $14.16 \pm 8.6$ & 11.5 & $0.049 *$ \\
\hline $\begin{array}{l}\text { significant p-value for the Wilcoxon paired test } \\
\text { level of } 5 \%\end{array}$
\end{tabular}

The results of the Beck Depression Inventory applied in pre- and post-dance moments are presented in Table 2. The comparison between pre- and post-test, as indicator of the effects of the intervention in the studied groups, showed no statistically significant difference.

Table 2 - Distribution of cases of depression in the pre- and post-test of the elderly attending the Senior Dance. $\mathrm{n}=20$

\begin{tabular}{lccc}
\hline Depression & Pre-test & Post-test & \multirow{2}{*}{$\mathbf{n}$} \\
\cline { 2 - 3 } & $\mathbf{n}(\%)$ & $\mathbf{n}(\%)$ & \\
\hline Normal or mild depression & $10(50.0)$ & $11(55.0)$ & \\
Depression & $10(50.0)$ & $9(45.0)$ & 0.831 \\
Total & $20(100.0)$ & $20(100.0)$ & \\
$\begin{array}{l}\text { There is no difference between the initial and final evaluation according to } \\
\text { the McNemar test, with significance level of 5\% }\end{array}$ &
\end{tabular}

As for the State-Trait Anxiety Inventory, trait anxiety showed a decrease of $7.4 \%$ in the score. However, this difference was not statistically significant $(\mathrm{p}=0.073)$. Regarding the difference in state anxiety, this was $12.6 \%$ and, in this case, was statistically significant $(\mathrm{p}<0.001)$. With regard to trait anxiety (tendency to perceive as threatening some circumstances that are not so), there was a reduction of $15.0 \%$ of cases. In the state anxiety (classified as temporary emotional state), the reduction was $25.0 \%$ of cases.

The post-test group of elderly showed higher scores in the four domains. The physical and environmental domains were significantly different in the pre- and post-test (Table 3).

Table 3 - Distribution of scores of quality of life domains of the WHOQOL-BREF in the pre- and post-test of the elderly attending the Senior Dance. $\mathrm{n}=20$

\begin{tabular}{lcccc}
\hline $\begin{array}{l}\text { WHOQOL-BREF } \\
\text { (score) }\end{array}$ & Pre-test & Post-test & $\begin{array}{c}\text { Difference } \\
\text { (\%) }\end{array}$ & p \\
\hline Physical & $12.71 \pm 2.64$ & $14.17 \pm 2.47$ & 11.4 & $0.011^{*}$ \\
Psychological & $14.29 \pm 1.72$ & $15.12 \pm 2.54$ & 5.8 & 0,211 \\
Social relationships & $15.06 \pm 3.03$ & $15.33 \pm 2.81$ & 1.7 & 0.652 \\
Environmental & $13.95 \pm 2.03$ & $15.65 \pm 2.03$ & 12.1 & $<0.001^{*}$ \\
Total & $69.5 \pm 7.6$ & $75.4 \pm 9.8$ & 7.8 & $0.004^{*}$ \\
\hline
\end{tabular}

*non-significant p-value according to the Wilcoxon paired test considering a significance level of $5 \%$

\section{Discussion}

The present study found a statistically significant difference pre- and post-test results of the Berg Balance Scale. Balance is a multi-organ function that depends mainly on the sensitive-sensorial and motor systems. As the Senior Dance is a physical activity of low to moderate intensity, the improved body balance of the elderly attending the Senior Dance can be explained most probably by decreased joint stiffness and improvement of nervous impulse conduction velocity than by increased muscle mass and strength.

A study carried out with elderly people in a Senior Dance group also showed positive results, in- 
dicating that this practice is a facilitating method for working with the elderly ${ }^{(10)}$. Positive results in relation to balance were also found for a shorter period of intervention (12 weeks) in a study conducted with 25 elderly participants of a Senior Dance program $^{(11)}$.

The score (in seconds) of the Timed Up and Go physical mobility test has a strong association with balance, gait speed and functional capacity, variables directly related to the propensity to fall. The time taken to perform the test correlates with the level of functional mobility. In this study, the time score of the Timed Up and Go pre- and post-test showed that in no instance the elderly had propensity to fall. Still, it is noteworthy that statistically significant difference was found in the Timed Up and Go test between the two moments of evaluation. A randomized clinical trial was developed to determine the effect of the Senior Dance in the lower limbs of fragile and sedentary elderly under residential care in the Czech Republic. This study concluded that the dance is causes improvement in the functionality of the lower limbs ${ }^{(12)}$.

Interventions of physical exercises involving aerobic exercise, balance training and flexibility are effective in to activities of daily living, as well to improve the quality of life ${ }^{(13)}$. However, dance movements used as intervention combines therapeutic and psychosocial benefits. These result from movements that can promote brain plasticity similar to the changes induced by physical exercise. Thus dance represents a great tool to promote health in the old age ${ }^{(14)}$.

Depression is a public health problem considered a major cause of disability worldwide. This disease can lead to limited social, physical and personal functioning ${ }^{(2)}$. The data presented in Table 2 show the prevalence of depression in $50.0 \%$ of the individuals at moments before the intervention and in $45.0 \%$ individuals after completion of the program. No statistically significant difference in symptoms of depression was found by applying the Beck inventory before and after the intervention. In this sense, the time of intervention may not have been enough to promote chan- ges in the psychological parameter of the elderly, as dance integrates physiological, psychological and sociological components and also provides an opportunity of living with music. Rhythmic moves of dancing promote functional, emotional and behavioral skills that are useful for the elderly, even despite the progression of disabilities. There is psychological evidence that dance moves prompt positive changes that facilitate self expression and communication among the elderly. Dance causes in special a softening of feelings of fear and isolation, and thus assists he development of better self-esteem ${ }^{(15)}$.

Normal aging implies a deterioration of cognitive functions that can lead to depression, functional dependency, low quality of life and decreased physical activity ${ }^{(16)}$. The Senior Dance has a high cognitive demand due to memorization of sequences of movement patterns and attention supported by intentional changes of movements ${ }^{(17)}$. Although this study has not established relationship between time of the intervention and reduction of symptoms, the duration of three months was not enough to cause positive effects in fighting the depressive state. However, it is known that when dance is included in programs designed to the elderly, this prevents cognitive decline and makes it possible to establish new social relations ${ }^{(18)}$.

There was no statistically significant difference in trait anxiety before and after the intervention period. These findings corroborate the results found in a study that showed no difference in scores for trait anxiety in a group of women enrolled in a dance program who were compared to a group that was not involved in the activity. However, statistically significant difference was found for state anxiety in the present study ${ }^{(2)}$.

The classification of trait and state anxiety evaluated at two different times showed the effects of the Senior Dance. This activity decreased the degree of state anxiety. The improvement in state anxiety help to eliminate unpleasant feelings of tension and apprehension consciously perceived by the elderly. It is 
important to consider the number of participants who initially showed depression and anxiety in this research, because both emotional states may impact the quality of life of these individuals ${ }^{(19)}$.

Dance activates areas of the brain associated with perception, emotions, executive function, memory and motor skills. Dancing movements affect procedural memory skills, such as motor and cognitive ${ }^{(13)}$. Moving the body while dancing increases the body's ability to encode rhythmic movements. This, in turn, has an effect in the gait of elderly people and, in therapeutic terms, these dislocations improve the balance of elderly ${ }^{(3)}$.

The evaluation of quality of life showed statistically significant differences in the physical and environmental domains. A study describing the positive impact of Day Centers in Portugal on the physical domain is in accordance with the present results. Another important point is the social aspect. The dance space can provide supervised activities and the possibility of establishing new bonds. This, in turn, produces a pleasant environment for the elderly. Considering the need to expand the spaces and practices that encourage social inclusion of the elderly, the dance is a form of recreation available to the public and easy to apply. It does not involve complex techniques that may pose risks to participants ${ }^{(20)}$.

Elderly who participated in the Senior Dance presented statistically significant increase in the scores of domains of quality of life. Therefore, dance can be regarded as an efficient possibility of intervention to improve the quality of life in old age ${ }^{(3)}$. In the present study, although $55.0 \%$ of the elderly did not know how to read or write, results were similar between literate and illiterate elderly when it comes to improvement of scores of all domains, but especially the physical and environmental.

Although there are few studies on the influence of Senior Dance on changes resulting from senescence, the present results show the benefits in physical, cognitive and social domains, improving the percep- tion of quality of life. The findings make demonstrate that the Senior Dance can be used as an efficient interdisciplinary strategy of health perception and promotion in favor of the elderly's welfare. The inclusion of the Senior Dance in programs of the Family Health Strategy and of the Family Health Support Center as complementary and integrative practices, besides physical benefits, promotes motivation to seek health promotion and prevention of the elderly ${ }^{(10)}$.

The improved results in the balance test after the intervention suggest reduced risk of falling and consequent social and economic demands. The decreased state anxiety, as well as the degree of anxiety experienced by individuals in the sample, endorses the inclusion of Senior Dance in permanent programs in Day Centers and also in health promotion actions directed to the elderly.

It is very important to stimulate brain functions. In this sense, as the Senior Dance demands physical and mental abilities from participants, this activity can be considered a low-cost option to be adopted in short and long-term institutions to stimulate the elderly'sr mental and motor functions.

It is recognized that the small sample size and lack of a control group represents a limitation that should be considered in future studies. But in spite of it, the present findings serve as valuable data to scholars on aging. It is expected that the results of this research widen the possibilities created in order to offer a better quality of life for older people through psychomotor education.

\section{Conclusion}

Based on the parameters evaluated, the study led to the conclusion that the Senior Dance positively influenced the balance and quality of life of the elderly. However, it was not efficient in all aspects of mental health, but only to anxiety classified as temporary emotional state. 


\section{Collaborations}

Gouvêa JAG and Antunes MD contributed to the project design, data collection, interpretation of results and writing of the article. Bortolozzi F, Marques AG and Bertolini SMMG contributed to the relevant critical review of the intellectual content and final approval of the version to be published.

\section{References}

1. Beckert M, Irigaray TQ Trentini CM. Qualidade de vida, cognição e desempenho nas funções executivas de idosos. Estud Psicol. 2012; 29(2):155-62.

2. Ho RT, Cheung JK, Chan WC, Cheung IK, Lam LC. A 3-arm randomized controlled trial on the effects of dance movement intervention and exercises on elderly with early dementia. BMC Geriatr. 2015; 15(1):127-33.

3. Guzmán-García A, Hughes JC, James IA, Rochester L. Dancing as a psychosocial intervention in care homes: a systematic review of the literature. Int J Geriatr Psychiatry. 2013; 28(9):914-24.

4. Chattopadhyay K, Singh AP. Anxiety and its impact on quality of life among urban elderly population in India: An exploratory study. Indian J Res Homeopathy. 2016; 10(2):133-41.

5. Cimirro PA, Rigon R, Vieira MMS, Pereira HMCTCG, Creutzberg M. Qualidade de vida de idosos dos centros-dia do Regado e São Tomé-Portugal. Enferm Foco. 2014; 2(30):195-8.

6. Gozzi SD, Bertolini SMMG, Lucena TF. Impact of academies of seniors: comparison of motor and cognitive ability between practicing and non practicing. Conscientiae Saúde. 2016; 15(1):15-23.

7. Eagles D, Perry J, Sirois MJ, Lang E, Daoust R, Lee J, et al. Timed Up and Go predicts functional decline in older patients presenting to the emergency department following minor trauma. Age Ageing [Internet]. 2016 [cited 2016 Oct 13];1(16):1-6. Available from: https://academic. oup.com/ageing/article/doi/10.1093/ageing/ afw184/2281663/Timed-Up-and-Go-predictsfunctional-decline-in
8. Sabet A, Azad A, Taghizadeh G. Test-retest reliability, convergent validity, and internal consistency of the Persian version of Fullerton advanced balance scale in Iranian community-dwelling older adults. Iran J Age. 2016; 10(4):18-29.

9. Rota DS, Pinto MH, Lourenção LG, Teixeira PR, Gonsalez EG, Gazetta CE. Anxiety and depression levels among multidisciplinary health residents. Rev Rene. 2016; 17(3):372-7.

10. Silva AFG, Berbel AM. O benefício da dança sênior em relação ao equilíbrio e às atividades de vida diárias no idoso. ABCS Health Sci. 2015; 40(1):1621.

11. Moser ADL, Cândido CM, Mello KCM, Rodrigues NC, Vidal C, Fontana MB. Effects of senior dance on balance of participants in a group of elder. Posturol Rehab J. 2013; 11(54):554-60.

12. Niemann C, Godde B, Voelcker-Rehage C. Senior dance experience, cognitive performance, and brain volume in older women. Neural Plast. 2016; 16(1):1-10.

13. Mclaren AN, Lamantia MA, Callahan CM. Systematic review of non-pharmacologic interventions to delay functional decline in community-dwelling patients with dementia. Aging Ment Health. 2013; 17(6):655-66.

14. Foster PP. How does dancing promote brain reconditioning in the elderly? Front Aging Neurosci. 2013; 4(4):1-2.

15. Vankova H, Holmerova I, Machacova K, Voliver L, Velete P, Martin A. The effect of dance on depressive symptoms in nursing home residents. JAMDA. 2014; 15(8):582-7.

16. Adam D, Ramli A, Shahar S. Effectiveness of a combined dance and relaxation intervention on reducing anxiety and depression and improving quality of life among the cognitively impaired elderly. Sultan Qaboos Univ Med J. 2016; 16(1):4753.

17. Merom MD, Cumming R, Mathieu E, Anstey KJ, Rissel C, Simpson JM, et al. Can social dancing prevent falls in older adults? A protocol of the dance, aging, cognition, economics (DANCE) fall prevention randomized controlled trial. BMC Public Health. 2013;13(1):447-56. 
18. Lobo BOL, Rogoli MM, Sbardelloto G, Rinaldi J, Argimon IL, Kristensen $\mathrm{CH}$. Terapia cognitivo comportamental em grupo para idosos com sintomas de ansiedade e depressão: resultados preliminares. Psicol Teor Prát. 2012; 14(2):116-25.

19. Hove MJ, Suzuki K, Uchitomi H, Orimo S, Miyake Y. Interactive rhythmic auditory stimulation reinstates natural $1 / \mathrm{f}$ timing in gait of Parkinson's patients. PloS ONE. 2012; 7(30):326-34.
20. Assari S, Lankarani MM. Race and gender differences in correlates of death anxiety among elderly in the United States Iran. J Psychiatry Behav Sci. 2016;19(2):2024-31.31. 